\title{
Integrate Long-Hour Course and Dual Learning Materials to Improve Students' Outcomes in an Electronic Course
}

\author{
Hsin-Hsiung Huang
}

\begin{abstract}
Students, which do not have enough course time to practice their hardware and programming skills in the physical class, usually cannot implement the system by using the traditional teaching method. The long-hour course, which contains not only three hours but also more practical time for students, is applied to the electronic course. To support the more exercises for the practical time in physical class, the concept of the dual learning materials, which extend the teaching materials to two different but high-related educational platforms, is provided to the long-hour course. The contributions of this study are as follows. First, the long-hour learning approach is explored to the students of University of Science and Technology. Second, the dual learning materials, including the software programming and the hardware educational platforms, the multiple-choice questions [12] and the source codes, are developed and utilized in the physical class. Third, each group should present their final results, including the finished programming codes, the slides and a video. Finally, the 16 groups, which contain 2 to 4 students, implement their projects and prepare the slides to present in the physical class.
\end{abstract}

Index Terms-Long-hour learning, student-orientation method, dual learning materials, students learning outcome, microcontroller, hardware-software integration.

\section{INTRODUCTION}

Many researches explored how to improve the learning outcome for the students. More and more studies transform the traditional method to the student-orientation teaching method to improve the learning outcomes [1]-[5]. Some researches develop the problem-based learning to enhance the skills for the students [1]-[3]. Some papers provide the flip-flop classroom teaching, which provides the learning material before physical classroom and then practices a lot of learning sheets or questions in the physical class, to improve the students' learning outcome [4], [5]. Li explores the student-centered approach instead of the traditional teacher-centered approach to evaluate the learning outcome differences by using the pre-test and post-test [6]. Huang et al. create the meaning environment to make the students learn the materials everywhere and then improve the learning outcome for students [7]. The study explores the contest-based approach, which encourages the students to design their own wheeled robots, join the contest and keep on improving their robots' hardware circuits and the programming codes, to enhance the practical skills for the

Manuscript received January 8, 2019; revised_March 29, 2019

Hsin-Hsiung Huang is with the Lunghwa University of Science and Technology, Taoyuan, 33306, Taiwan (Corresponding author; e-mail: pp022@mail.lhu.edu.tw). students in University of Science and Technology [8]. McLurkin develops the multiple robots system to improve the students in engineering fields and provide the low-cost robots for the advanced teaching and a wide range of courses [9]. Huang et al, develop the programming simulator, which teaches the multi-robot operation without the issue of collision, to make students learn the concept and skills by using the low-cost simulation platform [10]. Huang et al. consider the industry demand and develop the line following maze robot to train the students the skills of the hardware circuits and the firmware programming. When the students graduate from school, these skills can be used in the future work [11]. The research describes the tips to design the teaching materials to improve the students' attentions. Different materials styles may be considered for the students with the different education background [12]. Wang et al. provide the assessment to assess the students' attitudes, creative thing abilities, and the problem-solving skills [13]. Some researches provide the assessment guidelines to evaluate the students' learning outcomes during physical class or in the end of class [14], [15].

However, some researches do not discuss with the impact of the long teaching time for the students. If the longer teaching time is applied to the students, the students' learning outcome may be better. For the courses in electronic engineering and computer science, the skills of the programming and the integrated system should be practiced with the long time. Bloom presents the mastery learning to improve the students' outcome [16]. Dewey provides the concept of learning-by-doing for the students to do and learn the experience [17]. The research [18] discusses many approaches, which enlarge the teaching time and adjust the corresponding teaching activities, to improve the students' outcome. We observe that students cannot learn one project topic more detail because they usually do not have much time to practice the exercises. Moreover, the students often cannot ask for the teachers' help when they have the problems of the exercises, including the hardware and the programming.

The contributions of this paper are as follows. First, the course is planned to extend the longer physical time than the traditional approaches, which the teaching hour is usually three hours for each course. Second, two kinds of the teaching materials with high relationships are provided in the physical course to improve the students' outcome. For each topic, not only the programming simulation, but also the integrated system is provided to make students learn these topics deeply. Third, each group, which two, three or four students randomly determine by themselves [1], are encouraged to discuss the project topic, implement the functions of the project and prepare the slides to present. 


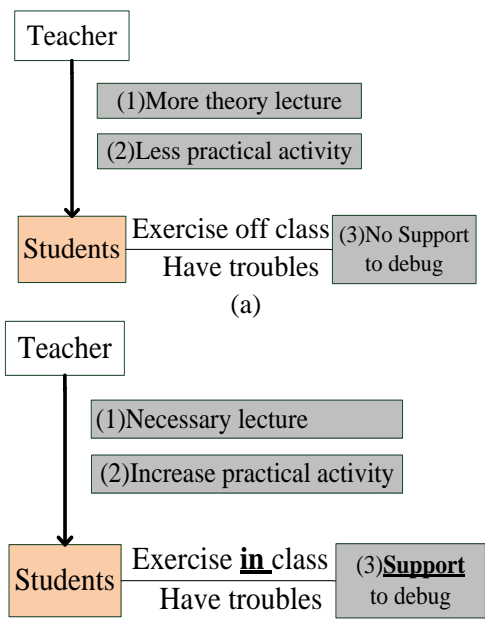

(b)

Fig. 1. Comparison of the traditional method and the proposed approach.

The outline of the paper is as follows. Section II discusses the teaching concept and teaching educational theory to improve the students' outcome. Section III illustrates the teaching method, including the course properties, the long-hour learning, the dual learning materials and the procedure of the physical class. Sections IV and V describe the results and discussion, and conclusions, respectively.

\section{TEACHING ConcEPT AND TEACHING EdUCATIONAL THEORY}

In this section, the teaching concept of the long-hour course and the educational theory are discussed.

\section{A. Teaching Concept}

There is a little challenge in the current high education for the students in University of Science and Technology. Some students are not interested in the theory courses. Some students are interested in the implementation of hardware circuits instead of the software or programming, and vice versa. How to arrange the course contents, including the educational platform, teaching and learning materials and course activities for group or students in physical class, is a very important issue.

Fig. 1(a) shows that the traditional approach, which there are many theory materials and little practical activities. However, the students may have the problems when they practice the exercises after the physical class. These difficult problems cannot be solved without the help of the teacher. Fig. 1(b) shows that the proposed approach, which is adjusted to keep the necessary materials and increases the practical activities, to improve the implementation skills of programming and hardware circuits. To deserve to be mentioned is that the problems, which the students meet in the class, can be fixed because the teacher is in the physical class. Hence, the advantages of the proposed approach are very suit for the students in University of Science and Technology and Science. And they can practice the practical skills with the supporting of the teacher.

\section{B. Teaching Educational Theory}

John Dewey [17] proposed the learning-by-doing approach to improve the students' learning outcome. For the technology-orientation students in University of Science and
Technology, the students usually need a little time to practice their skills of the programming and hardware circuits. However, students in most courses do not have enough time to practice the related skills of the software and hardware and they usually have the problems to ask help for help after the physical class.

In this paper, the teaching educational theory, which focuses on the skill improvement for the students of the electronic engineering in University of Science and Technology, is named as "more-do-more-learn". Fig. 2 shows the teaching activities and the teaching theory. The students are divided into $\boldsymbol{n}$ groups. The teaching flow contains the steps of 1) illustrating the knowledge-based materials, 2) practicing the skill-based materials for one environment (i.e. computer-based programming), 3) practicing the skill-based materials for the other extended environment (i.e. integrated system), 4) discussing the experimental content with the teacher, and 5) presenting a final project after several steps of (1)-(4). The course objectives are to improve the skills of the students, which are attended this course. The series topics are designed according to the course objectives. For each topic, the dual learning materials are also performed to the students to enhance the skills of programming for the two educational platforms, including the computer-based programming and the integrated systems. Finally, each group finishes the final project and prepares the presentation materials.

\section{METHOD}

In this section, the course description, the novel long-hour learning, the dual learning materials and the procedure used in the physical class are discussed.

\section{A. Course Description}

The course objectives are toward the directions of 1) Develop the software programming skills; 2) Teach the system integration of hardware circuit and firmware programming. 3) Learn the teamwork spirit to modify the project according to the teaching materials [19].

There are two educational platforms, such as the programming simulations and system integration. The programming simulation is only shown on PC screen by using the Dev C++ compiler [20]-[22]. Hence, the cost of this platform is very low. The system integration, which contains the microcontroller, the input modules, output modules, and the wires, is used to train the firmware programming skills for the main educational platform.

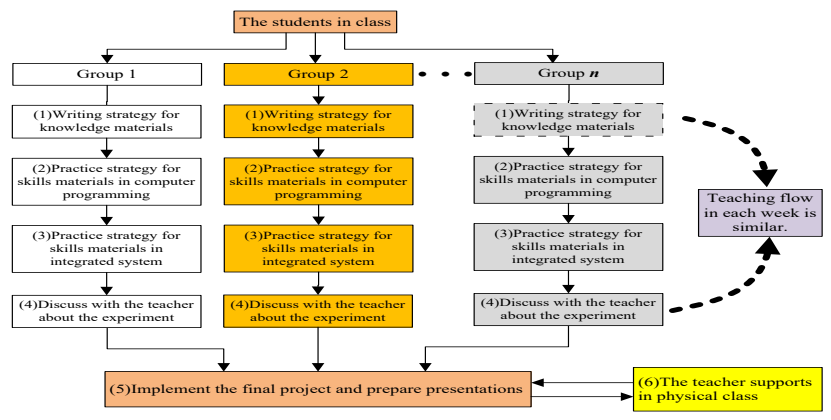

Fig. 2. The educational theory is more-do-more-learn for the series of planned exercises and the final project. 
Because the long-hour course contains six hours a week, there is very much time to plan the practical activities, such as the programming simulation and the integrated system. To perform the lecture and writing exercise takes two hours. To learn programming simulation, integrated system and experimental discussion between the teacher and group members takes four hours.

For each group, a final project, which is modified from the teaching materials or a new topic, is implemented and present in physical class. To explore the students' learning outcome, the successful percentage is used to see the impact of the long-hour course and the dual teaching materials. In this study, the successful rate ( $\mathrm{r}$ for short) is defined as:

$$
r=s / n
$$

where s and $\mathrm{n}$ are denoted the successful number of groups, which successfully prepare the project and present the slides and video, and total number of groups, which the notation $n$ is discussed in Fig. 2 and the last paragraph of Section II, respectively. The following is the long-hour learning.

\section{B. A Novel Long-Hour Learning}

In traditional method, the course planning may explain the course concept and content, and support the exercises for the students. For the students with the well educational degree and high motivated behavior, the traditional approach can teach them the basic knowledge and the students can extend to other applications. However, there are some problems for the students with low educational degree and motivated behavior. To extend the learning hours in physical class, provide the students the more learning materials and plan more time to practice these exercises may improve the students' outcomes.

Fig. 3 shows that the possible course planning to adjust the course topic to improve the students' learning outcomes. Compare with the traditional approach in left part, block 1) can extend to be considered how to illustrate the key point of the experiment for one week. Blocks 2) and 3) can be considered to how to extend the teaching materials to make students learn more exercises. For each topic, if we just put the teaching materials without high relationship, it cannot improve the students' learning outcomes. How to develop the proper extension teaching materials, which is high relationship with the teaching materials for these topics, is important to explore.

Long-hour learning may be one method to improve the students' outcome. Fig. 3 shows the possible course planning. For each topic, two different and high-relationship learning materials are developed. Generally speaking, the teacher may provide one source code for the platforms of the programming in personal-computer or for the hardware integrated system. To deserve to be mentioned is that the two teaching materials, which work in personal computer and the hardware integrated system, are similar but different. Hence, the two teaching materials are named "Dual teaching materials" in this paper. The students can have the learning experiences of developing the source codes in the difference educational platform.

Fig. 4 shows the traditional approach for one educational platform in the left part. The right part shows the materials for knowledge [12], the materials for skill (i.e. two source codes for the programming simulation on personal computer and the hardware-software system integration) and short answer questions [12]. Because both of the source codes are designed for the similar functions, students can learn more practical skills after implementing the source codes.

In the long-hour course, there is more time for students' practical exercise. The adjustment is for not only the teaching materials but also the corresponding activities of the physical classroom. Fig. 5 shows the difference between the traditional approach and the proposed approach in the paper. The left part is the traditional approach to teach the students with three hours a week. The right part is the extension for the practical activities to dual teaching materials. We know that the extension exercises for the programming simulation and the hardware integrated system makes students learn deeply.

Summary, the long-hour course contains the extensions in teaching materials and the exercise activities in physical classroom. Teaching materials are extended to dual teaching materials. To compare with the possible course planning for the traditional method, students can have more practical exercises and more time to master the skills of programming and the hardware circuits. The following is the description for the dual learning materials used in the long-hour course.

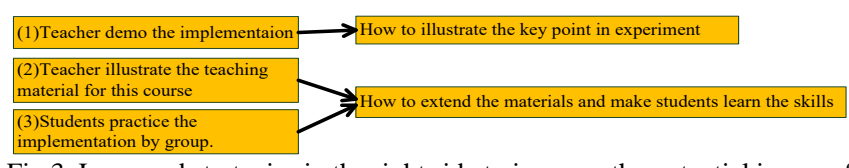

Fig.3. Improved strategies in the right side to improve the potential issues of the traditional method.

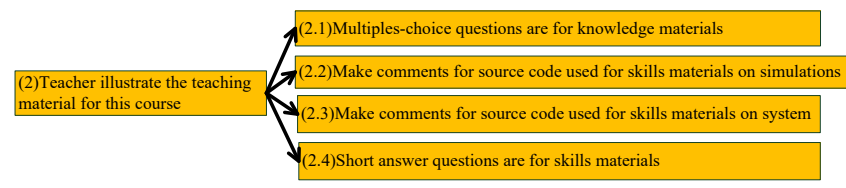

Fig. 4. Adjustment of the novel long-hour learning in teaching materials in block (2) of Fig. 3.

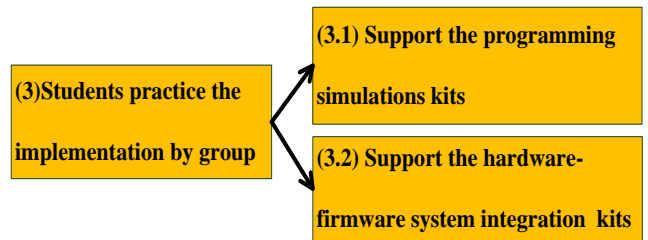

Fig. 5. Adjustment of the novel long-hour learning in students practical classroom activities in block (3) of Fig.3.

\section{Dual Learning Materials}

To extend the teaching materials, two different learning materials, including one programming simulation and the other system integration of the hardware circuit and the firmware programming, are developed. For a project topic, two dual learning materials are illustrated one by one. First, the programming simulation is first taught to the students. The students are asked to implement the exercises by group cooperative [1]. Second, the hardware-firmware system integration is shown to the students, too. The system integration will have the functions according to the firmware source codes. The dual learning materials are similar and the students can compare the difference between the programming simulation and the real system. Therefore, the 
students, whose educational background is different, still can study the project topics easily. Fig. 6 shows the advantages of applying dual learning materials for the students with the different learning background. Fig. 6(a) and (b) show the traditional approach, which usually applies the materials for just one kind of the educational platform. Fig. 6(c) shows that the dual learning materials can help the students with a wide range of the educational background. For a weekly topic, the functions and concepts of the exercises in programming simulations are the similar to ones in system integrations. Therefore, the student whose major is system integrations can learn the materials in not only the integrated systems but also the programming simulations. The following is the procedure of the physical course, which integrates the descriptions and concept of the subsections II.A, II.B and II.C.

\section{Procedure of the Physical Course}

To help the students to have the overall learning experience for implementing the final project, the course activity arrangement is roughly described as follows.

1) Illustrate the course content to the students by using the videos or others useful materials, which show the functions of the programming simulations and the hardware-software integration system. See the step (1) in Fig. 3.

2) Discuss the knowledge-based materials, such as multiple-choice questions and record the words for each line of the source codes [12], which are used in the later practical activities. See the steps from (2.1) to (2.4) in Fig. 4.

3) Guide the students to implement the programming simulations and they can easily know the skills of this exercise. See the step 3.1 in Fig 5 for reference.

4) Guide the students to further rewire the source codes of the programming simulations and modify the codes to run in the microcontroller-based system. In this stage, they can know the differences between the simulations in personal computer and the hardware-software integrated system and learn the practical coding skills for two different educational environments. See the step 3.2 in Fig 5 for reference.

5) After performing several exercises containing programming simulations and hardware-software integrated system, the group members are encouraged to determine the project topics, which they will finish in the following next weeks. See the step (5) in Fig. 2.

6) According to the project topic, the physical class is arranged to the implementation time for the group members. If they have implementation problems, the teaching will try to solve these bugs. This is very effectively to help the students to finish their project. In traditional teaching model, the students cannot easily look for the help. In this new long-hour teaching method, the teacher is in the physical class and students can ask for the teacher' help. See step (6) in Fig. 2 for the details. The templates for presentation are provided by the teacher. In subsection $\mathrm{C}$ in $\mathrm{VI}$, some discussion is described.

7) Finally, the group members can present their project.
Hence, they have the learning experience of overall project.

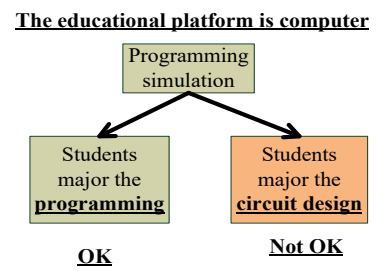

(a)

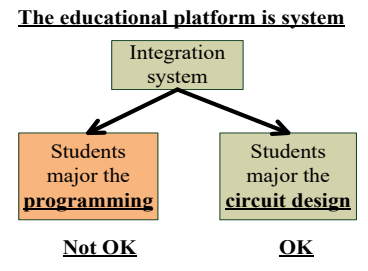

(b)

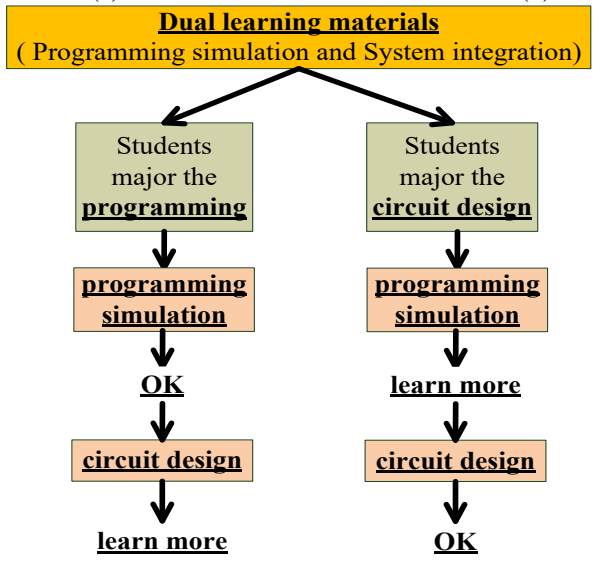

Dual learning materials make students learn widely. (c)

Fig. 6. Advantages of the dual learning materials for the students with the different learning backgrounds.

\section{RESUlTS AND DisCUSSIONS}

In this section, the final project, the two tasks for the most weekly topics, templates for the final presentations, and kinds of the final project are discussed.

\section{A. Group-Based Final Project with High Successful Rate}

The students are divided into 16 groups. All of 16 groups are finished their projects according to the discussions between the teacher and the students. The results are shown in Table I. According to the formula (1), the successful rate $(r)$ is $100 \%(=16 / 16)$. It means that the successful rate of the final project is quite good. The long-hour course, the dual teaching materials and the supporting of the teacher play the important role to help the students with the different learning backgrounds. To deserve to be mentioned, the teacher can help to solve the hardware or software bugs when the students have the problems of the final project.

After evaluating the qualities of their final implementations, the project results are that some of the implementations are very creative and well-done and some of them are just the same as the implementations, which the teacher demonstrates in the physical class. It means that some students' learning outcomes are quite good because some of the students can have the good skills to implement the project by their own designs. However, some students, which their learning outcomes are not good enough to finish a new project in the limited physical time, also have the learning experience to implement a project and prepare the presentation materials. Therefore, for the students with the different learning background and the motivation, the dual learning materials may help more students to learn the skills 
of implementation for the project than the traditional materials with only one kind of learning topics, i.e. only one kind of the programming simulation or the integrated system.

TABLE I: FINAL PROJECT RESULTS OF THESE GROUPS IN THIS COURSE

\begin{tabular}{lllll}
\hline \hline & Group 1 & Group 2 & $\ldots$ & Group 16 \\
\hline Implementation projects & OK & OK & $\ldots$ & OK \\
\hline Slides for presentations & OK & OK & $\ldots$ & OK \\
\hline Videos for functions & OK & OK & $\ldots$ & OK \\
\hline \hline
\end{tabular}

\section{B. Two Tasks for Most Weekly Topics}

There are two kinds of tasks for most weekly topics. One is the discussions between the students and the teacher when the group containing several students finishes the implementation of a week. The other is the video of the implementation.

For the first kind, the teacher guides this discussion and gives the hints of asking the questions. The students can be asked one-by-one. For a group containing students A, B and $\mathrm{C}$, the ordering is that student $\mathrm{A}$ can ask student $\mathrm{B}$, student $\mathrm{B}$ can ask student $\mathrm{C}$, and student $\mathrm{C}$ can ask student $\mathrm{A}$. Hence, students can enhance the memories of this weekly implementation. For the second kind, after the week implementation, the leader of each group will send the video, which demonstrates the function of this group. The video can show that what the students have finished in this week.
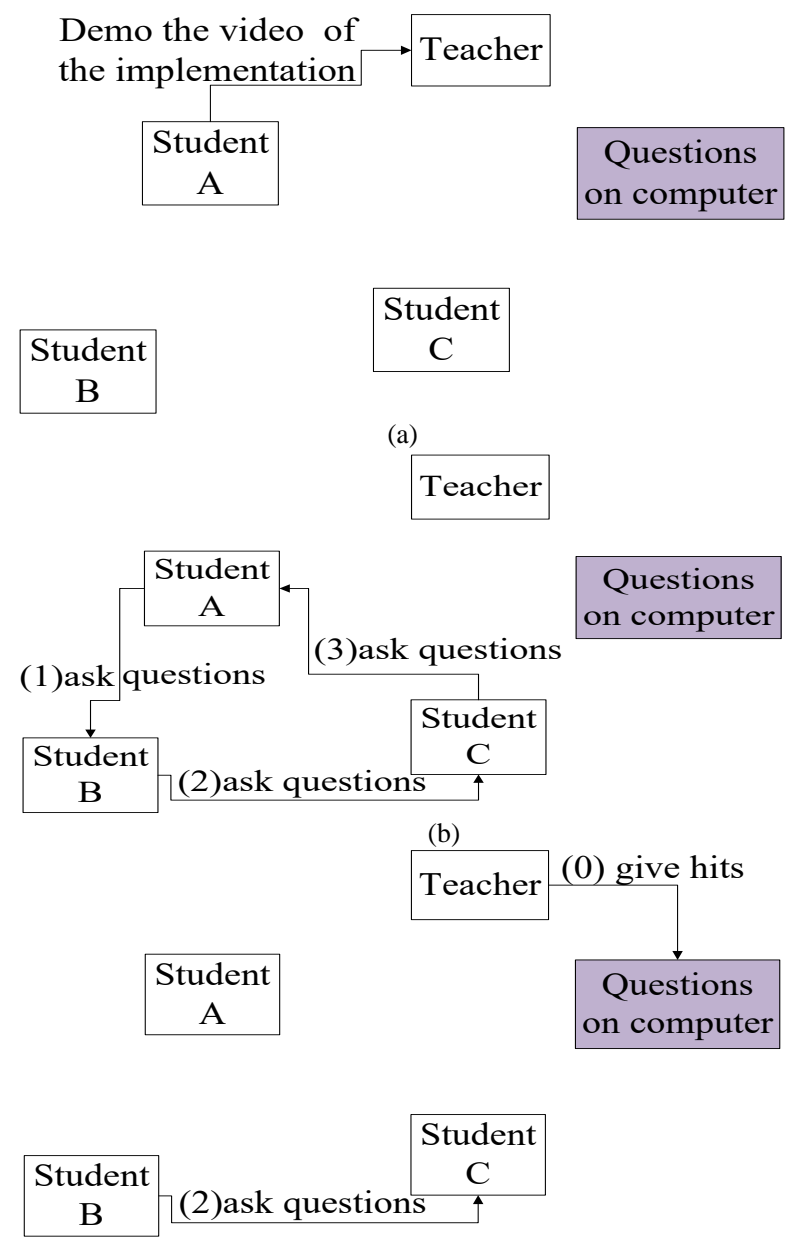

(c)

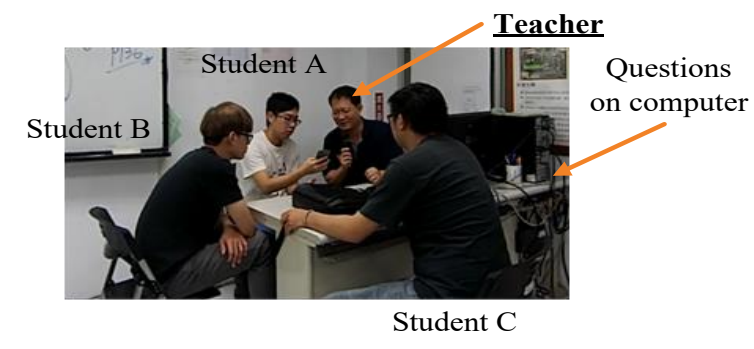

(d)

Fig. 7. Discussion between the teacher and the students after finishing the implementation in a week.

Fig. 7 shows the activities flow for each topic in a week. When the tasks in the physical class are finished by each group, they are asked to take a video about 10 seconds by using their cell phones. The teacher can check whether the group members finish their tasks or not. Fig. 7(a) show the student A demonstrate the video to show what they finish exercises in this week. Fig. 7(b) describes the order of asking questions for each group. Fig. 7(c) shows that if some students cannot ask the questions about the experiment clearly, the teacher gives the hits, which lists some questions about the experiment this week on the computer. Fig. 7(d) is the discussion between the teacher and the students that have finished the exercises in the physical class.

\section{Templates for Presentations}

The teacher provides the complete templates, which guides the students to think and fill the empty, to finish the project slides easily. Most of the presentation materials, such as the implementation programming or integrated system, the slides and the demonstrated video, are finished in the physical class. The teacher does not want to increase their learning loading because most of them have to finish their special topics at the third grade in University of Science and Technology. Moreover, most of them do not have the experience to prepare the presentation materials, so the teacher provides the templates to help them. If the students in class have the related experiences, the teacher may give them an incomplete template, which reduces the most materials and guidelines of the complete templates. Of course, the students must have the much experience and spend much time to prepare the presentations materials. The teacher should make the decision to the complete or incomplete templates for the students by consideration of the loading, the motivation, the learning experience and the prepared time. In the future, the teacher can determine which the complete or incomplete templates are suitable to the students in class?

\section{Kinds of Final Project}

Some groups implement the kind of the programming simulation and some groups finish the integrated system. If the teacher wants to improve the students' learning outcomes for the students in physical class, the wide range of the implementation projects may be a considerable decision. In the final project presentations, six and ten groups are selected the hardware (integrated system) and software programming as their final topics, respectively (Fig. 8 for reference). It means that $37.5 \%$ groups seem to be more interested in hardware integrated system. About $62.5 \%$ groups take the topics of software programming as their final presentations. 
It shows that the teacher should be planned the dual learning materials because the students may have the different learning background. The dual learning materials contain many exercises to make the students do more activities and learn more compared to the traditional approach, which usually contain the materials for one kind of the educational platform.

To improve the implementation skills of the programming and the integrated system, the long-hour learning is an effective method for the electronic course. The long-hour course can not only allocate much practical time in physical class but also provide the dual learning materials for the wide range of the students.

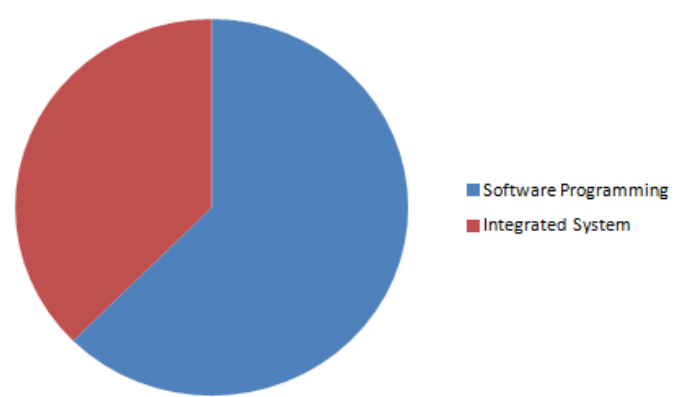

Fig. 8. Analysis of the project in the final presentation.

\section{CONCLUSION}

In this paper, the effective method is provided and evaluated by using the successful rate after performing the course. First, the long-hour course is planned and performed to improve the hardware and software integration skills for the students of University of Science and Technology. Second, the dual teaching materials, including the programming simulations and the hardware-software system integration, are provided the long-hour course. We observe that the long-hour course effectively makes the students learn the experiences of the practical skills to present their project after modifying the teaching examples, which they have learned in the electronic course. The study observes the good successful rate after performing the long-hour learning. There are 16 groups achieve the course goal of discussing to find the topics, finishing their implementation, and presenting their slides.

\section{REFERENCES}

[1] S. X. Tan and Z. X. Shen, "Hybrid problem-based learning in digital image processing: A case study," IEEE Transactions on Education, pp. 127-135, 2018

[2] S. C. Santos, "PBL-SEE: An authentic assessment model for PBL-based software engineering education," IEEE Transactions on Education, pp. 120-126, 2017.

[3] S. C. Santos, C. O. Figueredo, and F. Wanderley, "PBL-test: A model to evaluate the maturity of teaching processes in a PBL approach," IEEE Frontiers in Education Conference (FIE2013), 2013.

[4] J. P. Croix and M. Egerstedt, "Flipping the controls classroom around a MOOC," in Proc. 2014 American Control Conference, pp. 2557-2562, 2014.
[5] M. L. Fowler, "Flipping signals and systems - Course structure \& results," in Proc. 2014 IEEE International Conference on Acoustic, Speech and Signal Processing, pp. 2219-2223, 2014.

[6] Y. W. Li, "Transforming conventional teaching classroom to learner-centered teaching classroom using multimedia-mediated learning module," International Journal of Information and Education Technology, pp. 105-112, 2016.

[7] Y. M. Huang, P. S. Chiu, T. C. Liu, and T. S. Chen, "The design and implementation of a meaningful learning-based evaluation method for ubiquitous learning," Computers \& Education, pp. 2291-2302, 2011.

[8] H. H. Huang, J. H. Su, and C. S. Lee, "A contest-oriented project for learning intelligent mobile robots," IEEE Transactions on Education, pp. 88-97, 2013.

[9] J. McLurkin, J. Rykowski, M. John, Q. Kaseman, and A. Lynch, "Using multi-robot systems for engineering education: Teaching and outreach with large numbers of an advanced, low-cost robot," IEEE Transactions on Education, 2013.

[10] H. H. Huang, J. H. Su, and C. S. Lee, "Students-orientation software-based method for learning multiple robots cooperative operation," International Journal of Circuits, Systems and Signal Processing, vol. 10, pp. 208-214, 2016.

[11] H. H. Huang, C. S. Lee, J. H. Su, C. L. Yang and T. M. Hsieh, "Industry-orientation training course by line following maze robot," International Journal of Education and Information Technologies, pp. 105-112, 2011.

[12] Trentu.

[Online].

Available: https://www.trentu.ca/academicskills/documents/answeringshortansw erandessayquestions.pdf

[13] B. T. Wang, C. Y. Lee, C. C. Chiu, and C. W. Teng, "Assessment of student learning attitudes toward CDIO-based course design: A case study in Taiwan," International Journal of Information and Education Technology, pp. 932-936, 2017.

[14] Near. [Online]. Available: http://terms.naer.edu.tw/detail/1305655/

[15] Naer. [Online]. Available: http://terms.naer.edu.tw/detail/1314940/

[16] B. S. Bloom, "The search for methods of group instruction as effective as one-to-one tutoring," Educational Leadership, pp. 4-17, 1984.

[17] Learning-by-doing. [Online]. Available: https://en.wikipedia.org/wiki/Learning-by-doing

[18] Juang. [Online]. Available: http://juang.bst.ntu.edu.tw/JRH/JRH\%20Talks/Deep\%20bow1\%2020 18.pdf

[19] Lhuplan. [Online]. Available https://www.lhu.edu.tw/oapx/lhuplan/Query/TeachPlan/Plan_EQry.as px?tYear $=106 \& \mathrm{tTerm}=1 \& \mathrm{tSubNo}=\mathrm{EL} 23464 \& \mathrm{tTeaNo}=\mathrm{PP} 002 \& \mathrm{tClas}$ $\mathrm{sNo}=\mathrm{D} 104417 \mathrm{H}$

[20] Math. [Online]. http://www.math.ncu.edu.tw/ jovice/c++/boards/devcpp.htm

[21] Bloodshed. [Online]. http://www.bloodshed.net/devcpp.html

[22] Bytes. [Online] http://bytes.com/topic/c/answers/545639-what-does-system-cls-do

Available:

sin-Hsiung Huang becomes an IEEE member since 2010 and was born in Taiwan in Oct. 1974. He received the M.S. and Ph.D degrees in the Department of Information Computer Engineering and Institute of Electronic Engineering from Chung Yuan Christian University, Taoyuan, Taiwan, in 2000 and 2008, respectively. He is working toward the algorithm-related fields, such the applications of line-following maze robot for the shortest path problems and EDA algorithms for the VLSI, the floorplanner and performance-driven routing with the obstacles.

$\mathrm{He}$ is currently an associate professor in Department of Electronic Engineering, Lunghwa University of Science and Technology in Taoyuan in Taiwan. From 2000 to 2002 , He is a hardware engineering to design the Ethernet product at Accton Corporation, Hsin-Chu, Taiwan. From 2002 to 200 , He serves as a research and development engineering and focus on the chip design for the 10/100/1000 Mbps Ethernet MAC at TM-Technology Corporation, Hsin-Chu, Taiwan.

Dr. Huang is also an oversea member of Institute of Electronics, Information and Communication Engineers (IEICE for short) since 2009. Some publications are listed in IEEE conferences, including ISCAS, MWSCAS and ISIC, respectively. 